\title{
Artículos
}

\section{Cambios socioeconómicos en el siglo XXI en poblaciones indígenas amazónicas: retos actuales}

\section{Socioeconomic changes in the 21 st century in indigenous Amazonian populations: Current challenges}

\author{
Victoria Salinas Castro* \\ Richard E. Bilsborrow** \\ Clark Gray***
}

\section{Resumen}

La Amazonía ecuatoriana es una de las zonas bióticas más ricas de la tierra y con pluralidad de poblaciones indígenas. Este estudio pretende reconocer la situación de estas poblaciones, analizando sus tendencias en el tiempo mediante un estudio longitudinal sobre su situación demográfica y socioeconómica en la primera década del siglo XXI. Se observa una población joven y con alta fecundidad, así como ligeros decrementos en las actividades tradicionales de sustento y mejoramiento en el acceso a los servicios, propiciados por un contacto mayor con actores externos, como las empresas petroleras, los colonos y el gobierno, que a la par generan una complejidad socioambiental que constituye un reto ahora y hacia el futuro para el ejercicio de los derechos de los indígenas.

Palabras clave: poblaciones indígenas; Amazonía; Ecuador; modos de vivir; educación; tierra; medio ambiente; políticas de desarrollo.

* Universidad San Francisco de Quito. Dirección: Campus Cumbayá, Diego de Robles s/n, Quito 170901, Ecuador. Correo: victoriasalinas@yahoo.com ORCID: https://orcid.org/00000002-7007-7260

** University of North Carolina at Chapel Hill. Direccion: Chapel Hill, NC, 27599, Estados Unidos. Correo: richard_bilsborrow@unc.edu ORCID: https://orcid.org/0000-0002-0053-7356

*** University of North Carolina at Chapel Hill. Estados Unidos. Correo: cgray@email. unc.edu ORCID: https://orcid.org/0000-0002-6667-7909

Nota de los autores: Expresamos nuestro agradecimiento a las jefas y jefes de hogar de las comunidades indígenas que nos proporcionaron sus datos y sus experiencias, y a sus líderes comunitarios; al equipo de trabajo; a la Fundación Ecociencia; al Centro de Estudios de Población y Desarrollo (CEPAR), y a la Universidad de Carolina del Norte. Las investigaciones fueron apoyadas por las subvenciones R01 HD3877701 y R00 HD061752 de los Institutos Nacionales de Salud (NIH). 


\begin{abstract}
The Ecuadorian Amazon is one of the richest biotic areas on earth, with a plurality of indigenous populations. This study seeks to acknowledge the situation of these populations, by analyzing their trends over time through a longitudinal study of the demographic and socioeconomic situation in the first decade of the 21st century. It observes a young population with high fertility, as well as slight decreases in traditional livelihood activities and improved access to services, fostered by greater contact with external actors, such as oil companies, settlers and the government, which at the same time create a socio-environmental complexity that constitutes a challenge now and in the future for the exercise of the rights of indigenous people.
\end{abstract}

Keywords: indigenous populations; Amazon; Ecuador; ways of life; education; land; environment; development policies.

\title{
Introducción
}

En años recientes ha surgido mayor interés por las poblaciones indígenas con respecto a su situación socioeconómica, la preservación de sus culturas, el respeto a sus derechos humanos, la participación en la política de sus países, y su relación con el medio ambiente. Más de un millón y medio de indígenas habitan la Amazonía, y dada la importancia ecológica de esta zona en el planeta y su papel como el bosque tropical más grande y con la mayor biodiversidad, es tal vez la región del mundo que más llama la atención al respecto. La Amazonía ecuatoriana está catalogada como un hotspot de biodiversidad, y está documentada en varios estudios científicos (Finer, Jenkins, Pimm, Keane y Ross, 2008; Bass et al., 2010). Al respecto, las poblaciones indígenas tienen un papel importante debido a que, desde los primeros años de los noventa, el gobierno ecuatoriano les ha reconocido el derecho a ser dueños de grandes áreas geográficas, e incluso comparten con el Estado la responsabilidad del Parque Nacional Yasuní ${ }^{1}$ y la Reserva de Producción Faunística Cuyabeno. ${ }^{2}$

Las etnias amazónicas ecuatorianas han establecido relaciones con actores externos que les han generado efectos positivos y negativos, lo que los ha llevado a modificar sus patrones de vida sociales, culturales y económicos.

${ }^{1}$ El Parque Nacional Yasuní fue creado en 1979; es el mayor parque nacional en tierra firme de Ecuador y posee 1022736 ha. Dentro de su territorio y área de influencia habitan las etnias waorani, kichwa, shuar y los grupos indígenas en aislamiento voluntario tagaeri y taromenane. La UNESCO lo declaró Reserva Internacional de la Biosfera en 1989.

2 La Reserva del Cuyabeno pertenece al Sistema Nacional de Áreas Protegidas del Ecuador, y fue creada en 1979. Comprende 603380 ha y adentro se encuentran las etnias siona, siekopai, cofán, kichwa y shuara. Los dos son los lugares más biodiversos del planeta.

Estudios Demográficos y Urbanos, vol. 35, núm. 1 (103), enero-abril, 2020, pp. 83-116

http://dx.doi.org/10.24201/edu.v35i1.1768 
En este contexto, quisiéramos proporcionar en este estudio una perspectiva reciente y cuantitativa de una muestra representativa de la población indígena de la Amazonía ecuatoriana, teniendo como objetivo principal hacer un reconocimiento de su situación actual y de los cambios que se están presentado en la primera década del siglo XXI, así como sobre los posibles factores que pueden haber inducido tales cambios. Se pretende identificar las diversas dinámicas de cambio a través del reconocimiento de las nuevas situaciones respecto a las tendencias demográficas, la educación, los bienes y las actividades económicas en las comunidades de la Amazonía norte de Ecuador, que corresponden a cinco etnias: kichwa, shuar, cofán, siekopai (también conocida como secoya) y waorani.

\section{La Amazonía ecuatoriana}

La Amazonía ecuatoriana, grosso modo, puede enmarcarse históricamente en varios momentos. El primero corresponde al encuentro colonial (siglos XVI al XVIII), cuando sobresalió la fuerte reducción de la población indígena por la alta mortalidad (debida principalmente a las enfermedades traídas por la colonización), los asentamientos nucleados creados por las misiones y las encomiendas explotadoras (para hacerse de mano de obra), que provocaron, entre otras causas, la pérdida de autonomía política, económica y social. Un segundo momento histórico fue el de la expansión capitalista (el boom cauchero a finales del siglo XIX y principios del XX), cuando se presentaron relaciones desiguales de intercambio comercial entre las comunidades indígenas amazónicas y los actores foráneos, como la Iglesia, el Estado, las empresas y los primeros colonos (Santos, 1996; Fontaine, 2006). El tercer momento se enmarca dentro de la actualidad y corresponde al proceso de globalización, en el que se encuentran todas las sociedades y del cual las poblaciones indígenas no se han visto privadas, y que corresponde a un incremento e intensificación del intercambio comunicacional, de gente y de productos (materiales y no).

De forma más específica, se enmarcarían en este último momento las siguientes situaciones presentadas en las poblaciones amazónicas en el Ecuador. La primera fue el descubrimiento en 1967 de depósitos significativos de petróleo cerca de Lago Agrio, que dio lugar a una red de carreteras lastradas y caminos de tierra para colocar la tubería destinada a transportar el petróleo. Estas carreteras, desde luego, permitieron el avance de la frontera agrícola a través de la fuerte migración de los hogares, principalmente de las áreas rurales de la sierra (Santos, 1996; Murphy, Bilsborrow y Pichón, 
1997; Barbieri, Bilsborrow, Mena, Pan y Torres, 2003; Bilsborrow, Barbieri y Pan, 2004); la silvicultura y la explotación forestal, que pueden generar la extinción de especies (Rice, Sugal, Ratay y Fonseca, 2001; Asner et al., 2005); el cambio climático local y regional, que aparentemente provoca un aumento de la temperatura y la sequedad, complementando los procesos globales (Keller, Bustamante, Gash y Dias, 2009); y una expansión en la explotación de hidrocarburos, que ha producido grandes ingresos para el Estado. En 2003 se construyó una segunda tubería para duplicar la cantidad del petróleo transportado de la Amazonía ecuatoriana, estimulando una mayor inversión y explotación en áreas que anteriormente no eran económicamente atractivas, junto con una segunda fase de ampliación (y pavimentación) de las carreteras (Davis, Gray y Bilsborrow, 2015, Bozigar, Gray y Bilsborrow, 2016); además, la producción de biocombustibles ocasionó impactos ambientales como la contaminación de suelos y ríos, y del aire debido a la quema de gas.

De esta manera, los factores principales que influyen en los cambios recientes incluyen la explotación petrolera y la construcción de carreteras, lo que ha generado múltiples consecuencias sociales y ecológicas (Forman y Alexander, 1998; Perz, Caldas, Arima y Walker, 2007; Hecht, 2012; Bozigar, Gray y Bilsborrow, 2016), y una gran invasión de colonizadores agrícolas. A nivel social, las carreteras también acompañaron conflictos concernientes a la obtención de mayores accesos a la tierra y a la explotación de otros recursos naturales, al facilitar el acceso al mercado de los productores rurales colonos e indígenas, al integrar los sectores económicos, y al reducirse los costos de la movilidad espacial de las personas, el capital y la información.

Otros determinantes de la situación de la Amazonía ecuatoriana y de las etnias que la ocupan fueron las Reformas Agrarias y de Colonización decretadas en los años 1964 y 1973. La colonización consistió en el avance de la frontera interna exclusivamente para las tierras bajas amazónicas, lo que convirtió a la Región Amazónica en una zona de inmigración masiva, donde los colonizadores accedían a un promedio de 40 a 50 ha de superficie por beneficiario (Bilsborrow, Barbieri y Pan, 2004, con base en datos del Instituto Ecuatoriano de Reforma Agraria y Colonización). Dentro de este marco de apropiación de tierras por parte de los colonos surgió el concepto de comunidad indigena para las poblaciones nativas, que adquirió una función política y de sustento de su situación económica, social, demográfica y cultural, en busca de una legitimación de sus valores, modos de vida y prácticas, así como de su gestión del ambiente, bajo el supuesto de que dicha legitimación tenga validez frente a los actores externos, entre ellos el Estado (Chiriboga, 1984). 
Por tanto, la comunidad llega a tener una relación directa con el acceso a la tierra, que sustenta su producción y reproducción porque estos pueblos dependen de los recursos que ésta genera para su subsistencia (Pimentel, McNair, Buck, Pimentel y Kamil, 1997; Byron y Arnold, 1999). Las actividades agrícolas comúnmente representan los usos más importantes de estos recursos, siendo la fuente principal de las calorías del hogar (Beckerman 1987, citado en Gray, Bilsborrow, Bremne y Lu, 2008, p. 98), complementada con las proteínas obtenidas por medio de la caza y la pesca. Pero estas actividades se están alterando en las décadas recientes por los cambios en la flora y la fauna de la Amazonía ecuatoriana, los cuales responden a los procesos sociales, económicos y políticos ya anotados. Con tales situaciones se están presentando cambios socioeconómicos, ya que los hogares y comunidades indígenas tienen ahora mayor inserción en los mercados, por lo que han adoptado estrategias de vida más orientadas a éstos, como el trabajo asalariado, el turismo, la agricultura comercial y la venta de madera y otros productos forestales, incluso la carne silvestre (Gray, Bilsborrow, Bremner y Lu, 2008; Suárez et al., 2009).

\section{Las etnias amazónicas de este estudio}

La lucha indígena ecuatoriana es uno de los referentes del proceso indígena para América Latina, y entre sus ejes fundamentales destacan la lucha por el derecho a la tierra y los territorios, el fortalecimiento de la identidad, el reconocimiento de sus lenguas, la educación, entre otros. Una de las épocas más importantes al respecto es sin duda la década de los ochenta, con la constitución de la Confederación de Nacionalidades Indígenas del Ecuador (Conaie) (Macas, 2002), como una conclusión y síntesis del proceso organizativo y de lucha indígena $\mathrm{y}$, al mismo tiempo, con la emergencia de un sector social invisible en la convivencia nacional e internacional, que llegó a convertirse en actor social y progresivamente en actor político. La mayor muestra de la organización de los indígenas amazónicos fue el avance arrasador en la recuperación de sus territorios ancestrales, dada la colonización impulsada por el Estado extractivista (petrolero) de los años setenta. Por tanto, la lucha por sus territorios y la defensa de su identidad se encuentran entre sus principales objetivos, los cuales mantienen hasta ahora.

Este documento se refiere a cinco etnias indígenas amazónicas: kichwa, shuar, waorani, cofán y siekopai, las cuales se ubican en las provincias de Sucumbíos, Orellana y Napo. A continuación, se realiza un breve reconocimiento de cada una de estas etnias y, al tratarse de un estudio longitudinal, 
se colocarán referencias principalmente en relación con los datos de dos años: 2001 y 2012.

Los kichwas de la Amazonía Norte de Ecuador superan las 100 mil personas (Conaie, 2014). Este estudio trabajó con los kichwas situados a lo largo de los ríos Napo y Aguarico, en las áreas de las provincias de Napo, Orellana y Sucumbíos. Ésta es una de las etnias que más contacto ha tenido en los ámbitos social, político, cultural y económico. Con respecto al resto de la población, es la etnia que tiene más vinculaciones laborales con el Estado, pues los kichwas son contratados para trabajar con el resto de las etnias amazónicas como profesores, promotores de salud y capacitadores, entre otros empleos. Poseen un territorio de 2684000 ha aproximadas de ocupación y 1115000 adjudicadas. Tienen vinculación con áreas protegidas a través del Parque Nacional Sumaco Napo-Galeras.

Los shuar son miembros de la familia lingüística jivaroana y su territorio se ubicaba a lo largo de la frontera de Ecuador y Perú, en el oeste de la Amazonía. Cuentan con una población de 110 mil habitantes (Conaie, 2014). Debido a su alta densidad poblacional, muchos de los shuar del sur de las provincias de la Amazonía ecuatoriana empezaron a migrar en busca de tierras hacia las provincias de Orellana, Napo y Sucumbíos. Esto los coloca en la inusual situación de ser inmigrantes colonos, al mismo tiempo que indígenas (Lu, Bilsborrow y Oña, 2010). Su territorio es de 900688 ha de ocupación y 718220 ha legalizadas.

Los waorani cuentan con una población de 3000 personas, ubicadas en 24 comunidades (Conaie, 2014). Su idioma, wao tededo, está categorizado como una lengua aislada. Ha sido la última etnia contactada y asimilada en Ecuador (1958) a través del Instituto Lingüístico de Verano, seguido por las compañías petroleras. Con estas últimas han tenido fuertes presiones para "integrarse" a la sociedad nacional. Poseen un territorio de 2000000 ha de ocupación y 716000 ha legalizadas. Se encuentran vinculados al Parque Nacional Yasuní.

Los cofanes o a'i se encuentran en el sur de Colombia y en el norte de Ecuador, con una población de 15000 miembros y un total de 1000 personas en seis comunidades de Ecuador (Conaie, 2014). Se encontraban ubicados en la zona de Lago Agrio, pero fueron desplazados por la explotación petrolera y se desagregaron en asentamientos en áreas más profundas de la selva amazónica. Su territorio es de 330000 ha aproximadamente de ocupación y 47406 ha legalizadas; están en la Reserva de Producción Faunística Cuyabeno, la Reserva Ecológica Cayambe Coca y la Reserva Ecológica Cofán Bermejo.

Los siekopai, al igual que los cofanes, también se ubican en el noroeste de la Amazonía. Esta etnia está conformada por alrededor de 700 personas 
en Ecuador y Perú. Específicamente, en Ecuador cuenta con una población de 380 personas en tres comunidades (Conaie, 2014). Geográficamente viven a lo largo del río Aguarico y sus afluentes. Los siekopais cuentan con 39414.5 ha legalizadas y están vinculados con la Reserva de Producción Faunística Cuyabeno.

Demográficamente, estas poblaciones indígenas son jóvenes, pues la mitad o más de miembros tiene menos de 20 años, lo que refleja su alta fecundidad. Los kichwa y shuar tienen la fecundidad más alta, con una tasa global de fecundidad marital (TGFM) de 11.3 y 8.3 respectivamente, seguidos por los waorani (7.9) y los cofanes y siekopai (4.9). Estas poblaciones son esencialmente de fecundidad natural, con poco conocimiento y escaso uso de métodos modernos de regulación de la fecundidad: apenas $17 \%$ de todas estas poblaciones reporta el uso de métodos modernos y más del 70\% indica que no desea tener hijos (Salinas y Bilsborrow, 2016). Existe una aceleración del crecimiento de la población por la reducción de la mortalidad, que declina principalmente por las exitosas campañas de vacunación por parte del Estado, mientras la fecundidad se mantiene alta.

La forma tradicional de asentamiento de todas estas etnias era la selección de un lugar para vivir entre cinco y veinte años, pero las nuevas formas de apropiación de tierras han limitado esta forma tradicional de movilización. Una de las razones de ello se debe a las migraciones masivas de colonos agrícolas de la Sierra Andina, que han obligado a las poblaciones indígenas amazónicas a adentrarse en el bosque. Dado sus derechos comunitarios comunales de propiedad de la tierra e infraestructura comunitaria, como la escuela, el centro comunitario y/o la pista de aterrizaje o muelle, la vida seminómada ha cambiado casi totalmente.

Respecto a la integración a la economía de mercado, de las cinco etnias estudiadas, ninguna es una población puramente de subsistencia. Todas tienen personas involucradas en el mercado hasta cierto punto, pero esto varía ampliamente, al igual que los tipos de actividades generadoras de ingresos. Los shuar tienen la mayor integración al mercado y su relación es porque son inmigrantes recientes, y están dirigidos al trabajo asalariado y al cultivo de productos comerciales, incluso a la ganadería. Los kichwas poseen un nivel intermedio en la integración al mercado, con algunos pobladores orientados a una variedad de cultivos comerciales y a trabajos asalariados, y otros aún con una vida más tradicional. Los siekopai tienen un patrón mixto de integración al mercado, pasan poco tiempo en la producción de subsistencia, tienen una baja frecuencia de transacciones comerciales y asignan niveles intermedios de tiempo a las actividades comerciales, entre ellas el trabajo asalariado y la venta de madera y productos forestales no 
maderables (PFNM); en 2001 sólo esta etnia presentaba la actividad ganadera como actividad económica, pero resultó temporal. ${ }^{3}$ Los cofanes tienen el grado más bajo de integración al mercado; hasta el año 2000 estaban encaminados a las ventas modestas de PFNM y al turismo, pero debido al aumento de la inseguridad en el norte de la Amazonía ecuatoriana -por el incremento de los conflictos entre las Fuerzas Armadas Revolucionarias Colombianas (FARC), los paramilitares y las fuerzas armadas colombianas por la ejecución del Plan Colombia-, se limitó dicha actividad económica hasta casi anularla. ${ }^{4}$ Los waorani también tienen una baja integración al mercado, sólo están orientados al trabajo asalariado temporal con las petroleras y a la venta de animales domésticos y salvajes (Lu y Bilsborrow, 2011; Suarez et al., 2009).

Sobre las actividades de subsistencia, específicamente la caza, las etnias cofanes y waorani presentaron la mayor orientación a esta actividad en el pasado, seguidos por los kichwas, luego los siekopai, y por último los shuar. Los waorani y los cofanes pueden presentar la mayor orientación porque se encuentran más alejados de los centros poblados y de los mercados, y tal vez por el acceso a la rica biodiversidad de las reservas en donde viven. Es interesante resaltar que esta clasificación tiene precisamente el orden inverso de las etnias en términos de sus niveles de participación en la economía de mercado, anotado en el párrafo anterior. Las actividades de caza y pesca son actividades no sólo de subsistencia, sino también de roles de género y generacional, por lo tanto, esenciales para su identidad cultural (Lu, Bilsborrow y Oña 2010; Lu y Bilsborrow, 2011).

La agricultura es la principal base de subsistencia de todas estas etnias. Los cultivos primarios son yuca o mandioca y algunas especies de plátano. Todas las etnias, a excepción de los waorani, producen cultivos adicionales para la venta. Los cofanes cultivan maíz y cacao; los kichwas, los shuar y los siekopai, café, cacao y maíz. Las etnias shuar y kichwa tienen mayor participación en la economía de mercado y cuentan con áreas de cultivo significativamente más grandes y un mayor número de especies cultivadas.

${ }^{3}$ La empresa petrolera, como compensación para recibir permiso para explorar en su territorio, entregó a las familias cabezas de ganado y unos caballos, pero por no tener la costumbre ni recibir capacitación suficiente para cuidar estos animales ("no dan leche a los niños", por ejemplo), los animales se malograron y al final la mayoría murió.

${ }^{4}$ A pesar de esta situación, la actividad turística es uno de los principales referentes de vinculación con la economía de mercado para estas poblaciones, lo cual se evidenció en los diversos años que el equipo mantuvo relaciones con la comunidad. En 2001, durante los cinco meses de trabajo etnográfico, sólo una vez ingresó un grupo de turistas. En 2004 lo seguían manteniendo como referente, y lo mismo para 2012, a pesar de que la actividad turística sigue limitada. 
Sobre el uso de la tierra, los waorani, junto con los cofanes, fueron los más orientados a la subsistencia, con muy pequeñas chacras [granjas] dispersas.

Para reconocer su situación respecto al contacto con el resto de los actores y las poblaciones de la zona, se hará referencia al ingreso de los participantes de nuestro proyecto en sus comunidades. En 2001 el acceso se realizaba mediante botes, principalmente, y las comunidades que tenían acceso terrestre contaban sólo con caminos de tierra y casi nula presencia de servicio de transporte público, y en temporadas de invierno eran inaccesibles con carro. La excepción la constituían los shuar, pues contaban con carreteras cercanas en mejores condiciones. Para las comunidades waorani, el transporte se efectuaba sólo a través de carros, canoas o avionetas contratados. Para los cofanes, la comunicación se realizaba mediante canoas, y a una de ellas se accedía con caballos. Los siekopais disponían sólo de canoa. Para 2012, en algunas de las comunidades en las que se ingresaba con bote -si bien se seguía manteniendo este transporte-, el acceso ya era mixto mediante rancheras (camión semiliviano adaptado en forma artesanal para el transporte público rural), autobuses y canoas, debido al ingreso de las petroleras y a la nueva construcción de carreteras, lo que disminuyó la distancia y el tiempo de cuando se transportaban sólo por los ríos. En las zonas donde sólo se ingresaba con carro, en su mayoría las carreteras ya se encontraban lastradas o pavimentadas y con servicio de transporte público hacia sus comunidades o sus cercanías. Sólo en una de las comunidades waorani el ingreso se seguía realizando por avioneta. Las comunidades siekopais cambiaron su forma de ingreso de bote a transporte por carretera.

Muchas de estas poblaciones indígenas se encuentran vinculadas con las actividades petroleras porque las actividades extractivas y/o sísmicas se realizan dentro de sus territorios. Mediante los acuerdos de estas empresas con las comunidades, la población se vincula laboralmente por la contratación de mano de obra no calificada. Es importante anotar que, de las 32 comunidades de este estudio, 19 mantuvieron relaciones con las actividades petroleras (en 2001 y 2012), y casi todas con al menos una persona vinculada laboralmente.

Esta breve contextualización da cuenta de la complejidad de estas poblaciones amazónicas, de sus diferentes presiones, oportunidades, preferencias y valores culturales que, en conjunto, influyen en las decisiones que toman las personas sobre cómo usar la tierra y los recursos. A medida que estos factores cambien, también lo harán sus decisiones. 


\section{Enfoque teórico}

En América Latina se ha reconocido la complejidad de las decisiones de los hogares rurales para sobrevivir en las condiciones de incertidumbre debidas a las vicisitudes del clima y a los precios de los productos en el mercado. Distinguiendo el hogar más que individual como la unidad principal de decisiones, los sociólogos de la región desarrollaron la "teoría de sobrevivencia del hogar campesino" (Argüello, 1981). Vieron cómo los hogares distribuían a sus miembros de edad laboral en diferentes actividades económicas y en diferentes lugares, según sus capacidades y educación en relación con los tipos de trabajo y los ingresos correspondientes. Usando la definición de modos de vivir para referir "las capacidades, activos y actividades necesarias para vivir", y aprovechando la perspectiva de la teoría de modos de vivir o livelihood theory (Ellis, 2000), se puede reconocer la variedad de actividades económicas que puedan escoger las poblaciones indígenas de la Amazonía, comenzando con las tradicionales, como la agricultura de subsistencia, la caza, la pesca y la extracción de productos del bosque para comida y medicinas. Al pasar el tiempo surgen mayores contactos con actores externos, como colonos, gobierno, empresas extractivas y pueblos en crecimiento, que abren nuevas opciones como la agricultura y la ganadería comercial y el empleo fuera de la comunidad, especialmente para las personas con más educación (con secundaria). Según la teoría, el hogar tiende a cambiar la distribución de los miembros en los distintos tipos de actividades de acuerdo con los cambios en las condiciones del medio ambiente (véase más adelante lo relacionado a la caza), los precios de los productos, los sueldos y las oportunidades de empleo. En este modelo, el papel de la educación para formar capital humano capaz de abrir nuevas opciones está claro, al igual que los efectos de la inversión en infraestructura como carreteras y tecnología agrícola. Se considera a la migración fuera del hogar como un instrumento integral de los modos de vivir, con o sin la expectativa de recibir remesas después. Es un modelo comprehensivo y flexible para analizar los factores que estimulan los cambios en el tiempo.

Existe también otra teoría para explicar cómo los cambios demográficos pueden inducir diferentes tipos de respuestas en los hogares para mantener o mejorar sus condiciones de vida: la "teoría de la respuesta multifásica". Inicialmente, la teoría original de Davis (1963) consideraba las respuestas factibles demográficas, como postergar uniones, reducir la fecundidad o emigrar del hogar, pero después Bilsborrow (1987) la amplió al incluir posibles respuestas como la expansión del área agrícola (extensificación de la agricultura), los mejoramientos tecnológicos en el agro para producir más 
por unidad de tierra o mano de obra (intensificación de la agricultura), y el trabajo no agrícola, de acuerdo con la cercanía de los mercados y los sueldos. Un punto clave es que es similar a la livelihood theory al tomar en cuenta todas las opciones económicas, pero tiene una extensión fundamental al considerar que cuando un cambio o respuesta ocurre, esto reduce las presiones para otras respuestas. En la Amazonía, durante la década observada, hay mayores actividades petroleras en ciertas regiones (y menos en otras), ampliación en las vías de transporte terrestre que dan acceso a los mercados y al empleo, expansión en los proyectos de desarrollo y en el papel del Estado en general en la región, inmigración aun de otras partes de Ecuador de personas en busca de tierra o trabajo, y crecimiento rápido de las áreas urbanas.

Utilizamos la livelihood theory pues la teoría de la respuesta multifásica requiere medir y comparar los tamaños de cambios para ver "tradeoffs" en los cambios que van más allá de las posibilidades de este documento.

\section{Datos y métodos}

En el año 2001 la Universidad de Carolina del Norte (UNC), junto con la Fundación Ecociencia y el Centro de Estudios de Población y Desarrollo (CEPAR), realizaron un estudio multidisciplinario, con metodologías cuantitativas y cualitativas, cuyo objetivo fue determinar los factores demográfi$\cos$, socioeconómicos y biofísicos que influyen en el uso de la tierra y los recursos de cinco poblaciones indígenas. La recolección de datos en 2001 involucró dos fases de investigación: 1) un estudio etnográfico en ocho comunidades indígenas (tres de la etnia kichwa y una comunidad de cada una de las etnias shuar, waorani, ${ }^{5}$ cofán y siekopai), llevado a cabo durante cinco meses; y 2) dos encuestas en hogares y a sus líderes comunitarios en 28 comunidades adicionales (Lu y Bilsborrow, 2011).

En la fase etnográfica el número total de hogares estudiados fue de 120, compuestos por 677 individuos. Las herramientas que se utilizaron para la recolección de datos etnográficos incluyeron observación participante, asignación de tiempo, diarios económicos del hogar y cuestionarios formales que cubrían temas demográficos, producción agrícola y uso de los recursos, así como actividades socioeconómicas del hogar. Los datos de caza se recopilaron mediante entrevistas posteriores y cuestionarios de datos poscaza. Se estudiaron diferentes tareas laborales y su variación por edad, sexo, tamaño y composición del hogar y origen étnico mediante el método de asig-

${ }^{5}$ La comunidad waorani se dividió en dos al principio del proyecto.

Estudios Demográficos y Urbanos, vol. 35, núm. 1 (103), enero-abril, 2020, pp. 83-116 http://dx.doi.org/10.24201/edu.v35i1.1768 
nación de tiempo al control, datos que se recolectaron por medio de visitas aleatorias al hogar. En la segunda fase de encuestas se trabajó en 36 comunidades, incluidas las ocho de la fase etnográfica. La encuesta en hogares incluyó dos cuestionarios, uno para el jefe del hogar y otro para la jefa. Los entrevistadores masculinos administraron el cuestionario al jefe de hogar (generalmente varón) y la entrevistadora femenina a la jefa de hogar; cada entrevista duró aproximadamente una hora. El cuestionario del jefe cubría el historial de migración, tenencia y uso de la tierra, producción y venta de cultivos y ganado, empleo asalariado, caza y pesca, y búsqueda de alimentos, entre otros temas. El cuestionario del cónyuge incluyó una lista de los miembros del hogar, su historial migratorio, la emigración de dichos miembros, los bienes del hogar, la fecundidad, la mortalidad, y las enfermedades y la atención médica, entre otros temas. También se implementó una encuesta a nivel comunitario a los líderes de la comunidad sobre el tamaño de la población, la infraestructura y la organización comunitaria, la ubicación relativa respecto a las carreteras y principales ciudades, los medios y la frecuencia del transporte, y los contactos con instituciones externas.

Las comunidades fueron seleccionadas para representar no sólo a las cinco etnias, sino también a una diversidad de tamaños de población y ubicaciones con respecto a caminos, ríos y acceso a ciudades y mercados; esta metodología se llama "controlled selection" (Goodman y Kish, 1950; Kish, 1965), y es apropiada cuando la muestra no es muy grande en relación con las características que se quieren tomar en cuenta para que sea representativa de las comunidades de interés (véase el Mapa 1).

Dentro de cada comunidad de la muestra, para la selección de los hogares se procedió de la siguiente forma: si la comunidad tenía menos de 22 hogares, se aplicaban los cuestionarios a todos ellos; y si tenía más de 22 hogares, se seleccionaron mediante muestreo aleatorio, con base en un mapa con la ubicación de todos los hogares ocupados, el cual fue preparado junto con los líderes de la comunidad.

En 2012, la UNC y la CEPAR implementaron dichos cuestionarios a los mismos hogares encuestados en 2001, pero con las modificaciones necesarias para reconocer los cambios presentados. De las 36 comunidades entrevistadas en 2001, sólo se trabajó con 32 en 2012 (tres no participaron debido a problemas logísticos, y en otra comunidad habían migrado todos sus miembros).

En total, se dispone de 464 hogares con datos completos para el año 2001, así como de 601 para 2012. Creció la muestra para este año porque se incluyeron los nuevos hogares derivados que se formaron después de 2001 debido a divorcios o, principalmente, porque los hijos se casaron o unieron. 


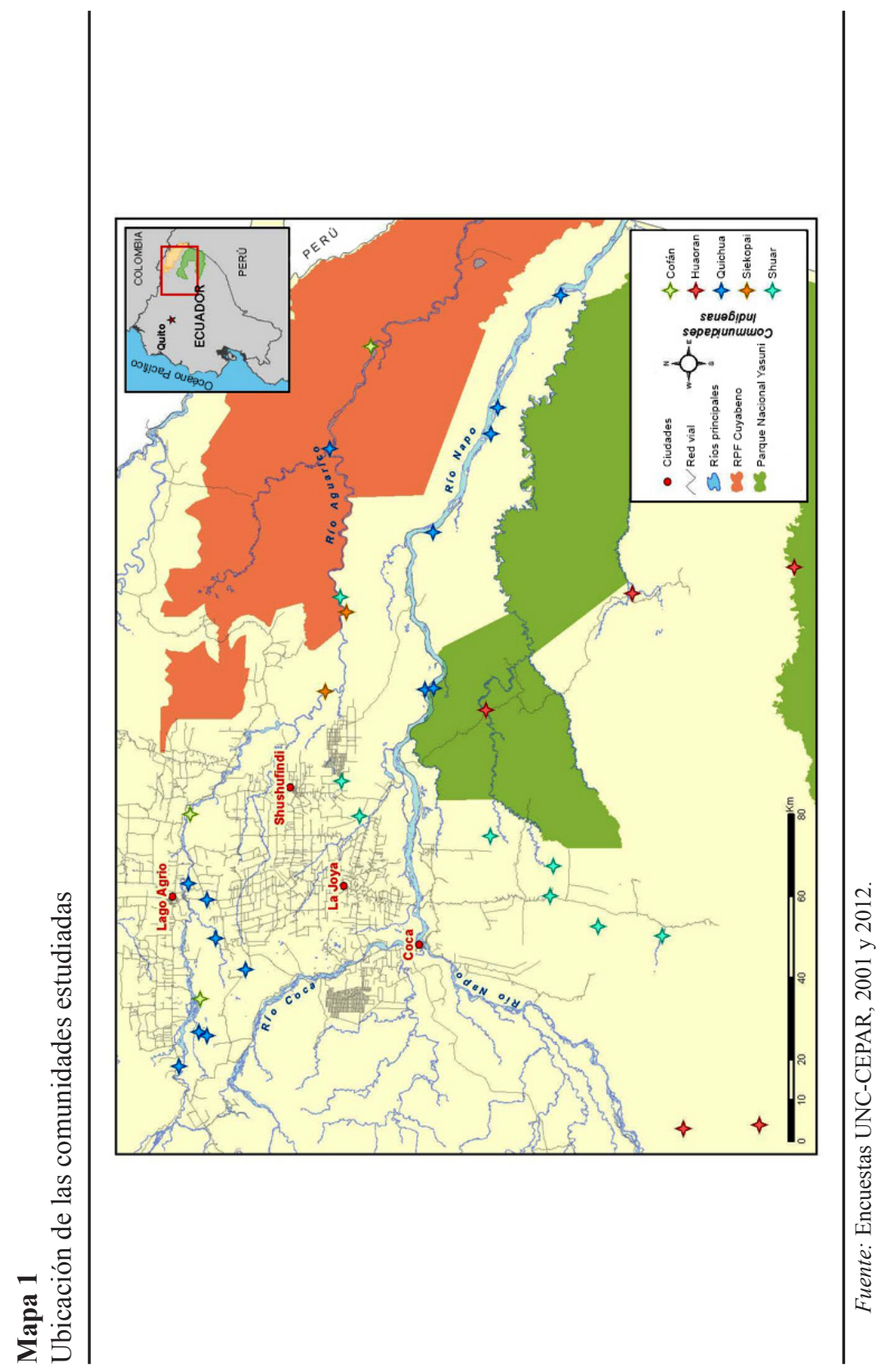


Menos de 10\% de hogares de 2001 no se pudieron entrevistar en 2012 debido a que salieron de sus comunidades.

Con los datos recolectados en estos dos años, éste es un estudio longitudinal. A fin de caracterizar los cambios que se han presentado en los aspectos socioeconómicos de las comunidades durante los once años, se presenta la información en varias dimensiones, partiendo de su situación demográfica y educación, para pasar a lo económico, indicado por sus bienes y actividades económicas, tanto tradicionales como nuevas. Los niveles de los valores de las variables analizadas y sus tendencias permitirán comparar los hogares y hacer un reconocimiento de las características y diferencias por etnia, además de distinguir los patrones de cambio.

La metodología utilizada es cuantitativa, mediante un análisis de frecuencias de los componentes a ser estudiados. Sin embargo, se enfatiza que los resultados y sus análisis corresponden a una triangulación bibliográfica de otros autores mencionados antes y, más importante aún, a datos cualitativos de estudios etnográficos elaborados en relación con la encuesta de 2001 y a decenas de conversaciones adicionales realizadas con hombres y mujeres de estas comunidades en los años 2000, 2001, 2004, 2009, 2012 y $2013 .{ }^{6}$

\section{Resultados}

\section{Situación demográfica}

Un primer elemento a considerar es el reconocimiento de la situación demográfica y sus cambios posibles en los años 2001 y 2012. A nivel general, la estructura por edad de la población encuestada de las cinco etnias no tuvo mayor modificación. Esto porque, para 2001, el 53\% tenía menos de 15 años, mientras que para 2012 su reducción fue pequeña, al 49\% (Cuadro 1), consistente con una baja disminución en los niveles de la fecundidad (Davis, Gray y Bilsborrow, 2015). Como consecuencia, la razón de dependencia de niños a nivel global (población de edad 0-14 dividido por la población 15$59)^{7}$ mejoró un poco, de 1.18 a 1.04, aunque aún refleja una sociedad con alta fecundidad. Ello, como veremos más adelante, tiene implicaciones para sus actitudes en relación con su futuro.

${ }^{6}$ La primera autora de este estudio fue una de las doce etnógrafas que participó en el año 2001, fue presentadora de los resultados a las comunidades en 2004, luego coordinadora del proyecto en 2012, e investigadora en un estudio cualitativo en 2013.

7 Normalmente los demógrafos usan la población de 65 y más para la población mayor de edad, pero los datos disponibles eran para 60 y más, una pequeña diferencia que no cambia las comparaciones y las conclusiones del texto. 


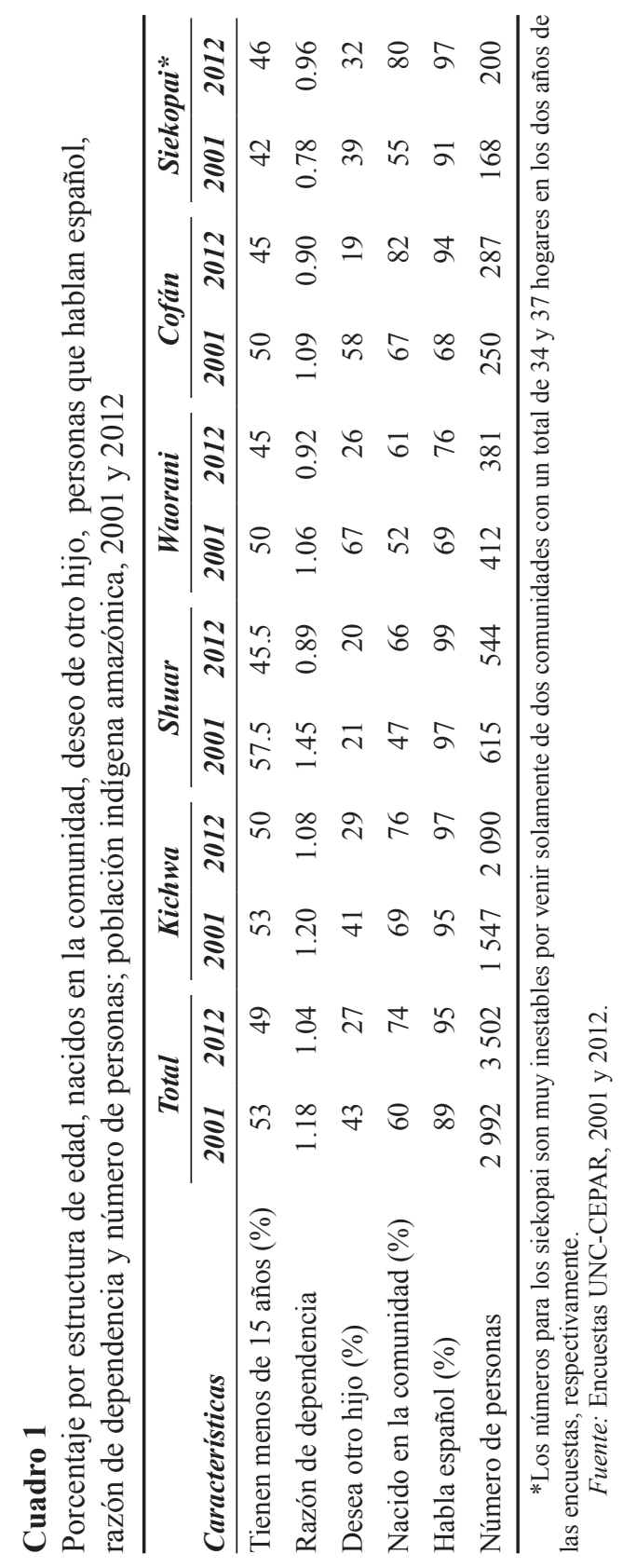


A pesar de que se evidencia que la disminución de su fecundidad es mínima (la tasa global de fecundidad marital de 10.6 en 2001 bajó a 9.3 en 2012, según el estudio realizado por Salinas y Bilsborrow, 2016, en función de estos mismos datos), cuando se investiga si desean tener otro hijo, hay un descenso de tal deseo entre los dos años, de 43 a 27\%. La etnia que presenta la baja más reveladora es la waorani, de $67 \%$ en 2001 a $26 \%$ en 2012. Le sigue la cofán, de 58 a $29 \%$. La que menos presenta el deseo de no tener otro hijo es la shuar, pero en 2001 tenía ya un porcentaje muy bajo de hogares que deseaban tener otro hijo (apenas 21\%). Estos datos sugieren que la fecundidad puede comenzar a bajar en un futuro muy cercano.

Un cambio demográfico interesante es el porcentaje de la población que había nacido en la comunidad, el cual subió de 60 a 74\%. Esto se debe principalmente al hecho de que los shuar habían migrado del sur de la Amazonía ecuatoriana en décadas anteriores (de 2001), mientras que, luego de once años, han tenido hijos nacidos en las nuevas provincias de residencia, haciéndose comunidades estables. También sucede esto para las otras etnias, que están dejando de ser seminómadas, especialmente los waorani. Se podría argumentar que ello se debe, en parte, a la infraestructura construida por el Estado, como escuelas (en los momentos de las encuestas había una por comunidad, independientemente del número de hogares), casas comunales, paneles solares y, a veces, promotores de salud con medicinas y proyectos de desarrollo.

Otra característica importante de las poblaciones indígenas -que es crucial para su participación en la sociedad nacional- es el conocimiento del idioma español. En total, para 2001, el $89 \%$ de la población encuestada hablaba español; para 2012 subió a 95\%. Los cofanes tienen el cambio más fuerte (de 68 a 94\%), seguido por los waorani (de 69 a 76\%). Así, el conocimiento del español ha dejado de ser un factor limitante para su participación en la sociedad y el mercado de trabajo, pero el nivel de entendimiento y habla muchas veces es débil, sobre todo para las mujeres y los mayores (resultados obtenidos de la observación participante y del trabajo etnográfico). A continuación, revisaremos otra característica que sugiere que este indicador seguirá cambiando rápidamente en relación con su participación en la sociedad.

\section{Educación}

La educación es un tema importante porque tiene relación directa con los valores culturales y la participación socioeconómica en la sociedad. La 
educación primaria terminada por los adultos presenta un cambio significativo en la década analizada porque de 53\% en 2001, aumentó a 70\% en 2012 (Cuadro 2). Mientras tanto, la población con educación secundaria también subió, de 5 a 13\%; dicho cambio es sustancial porque esta población tiene más amplias posibilidades de empleo que la que tiene sólo educación primaria. Otros datos aún más interesantes son los de la asistencia actual a establecimientos educativos, pues serán las personas educadas en el futuro cercano. Se aprecia un gran cambio educativo: primero, la asistencia a la escuela por parte de los niños (entre los 6 y los 11 años de edad) de 90\% en 2001, creció a $97 \%$ en 2012, y la asistencia a la escuela (entre los 12 y los 17 años) subió de 65 a 77\%. Durante la década entre ambas encuestas, volvió a ser casi universal la educación de los jóvenes en las escuelas, a pesar de la inconveniencia física de eso, pues para la mayoría de las comunidades implica financiar la movilización y la estadía en los pueblos de colonos o en otras comunidades indígenas donde se encuentran las escuelas.

Por etnia, respecto a la culminación de la educación primaria por parte de los adultos, la cofán es la que más puntos subió, de $20 \%$ en 2001 a $48 \%$ en 2012. Respecto de la finalización de la educación secundaria para adultos, nuevamente esta etnia presenta la mayor alza, de sólo 3\% en 2001 a 14\% para 2012. Hay que anotar que, si bien los datos se presentan con tendencias a crecer en las cinco etnias, aún los niveles de educación seguían bastante bajos en comparación con la población total ecuatoriana ( $56 \%$ de los adultos entre los 20 y 24 años habían completado la educación secundaria, según los datos del censo de población de 2010). De las cinco etnias, la siekopai tiene el mayor porcentaje de personas adultas que habían culminado la educación secundaria, tanto en 2001 (11\%) como en 2012 (19\%), lo cual les fue facilitado por tener una escuela en la comunidad más grande.

En lo que corresponde a la asistencia a secundaria, los kichwa y los siekopai son los que experimentaron los cambios más significativos (de 61 a $79 \%$ y de 67 a 90\%, respectivamente), les siguen los waorani (de 72 a 88\%), los shuar no presentan mayores cambios, y los cofanes tienen tendencias a la baja ( 68 a $56 \%)$.

\section{Bienes y pobreza}

En todas las etnias se presenta un aparentemente amplio aumento en las condiciones de vida entre 2001 y 2012, que se refleja en primera instancia en las características de las viviendas. Las casas con techo mejorado (que cambiaron techos de palma a zinc) subieron de manera sustancial a nivel 


$$
\begin{aligned}
& \text { วิ } \\
& \text { के } \\
& \text { : }
\end{aligned}
$$

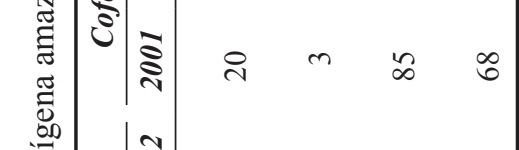

$$
\begin{aligned}
& \text { 苛 }
\end{aligned}
$$

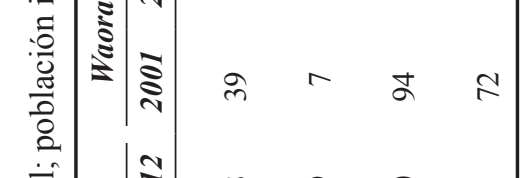

$$
\begin{aligned}
& \text { 离 } \\
& \text { : }
\end{aligned}
$$

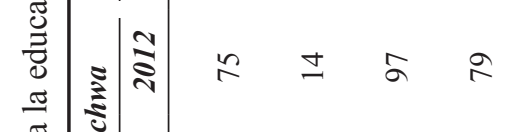

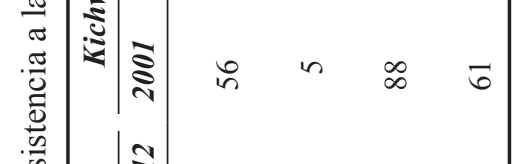

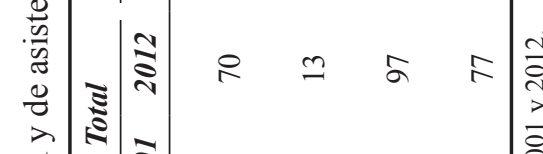

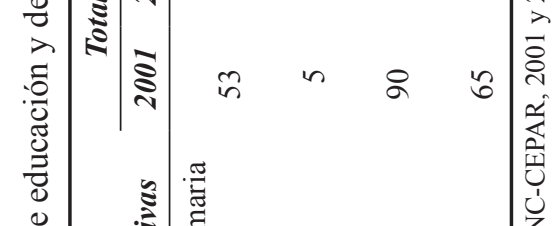

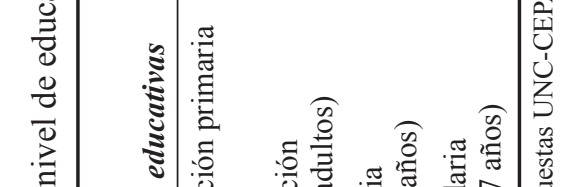

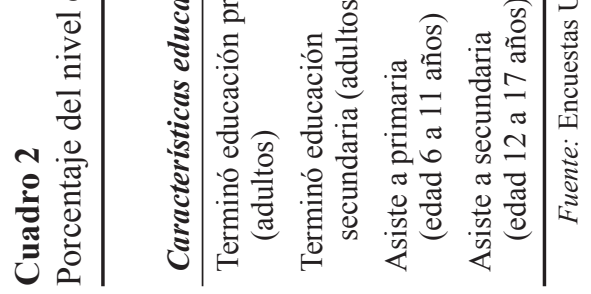


global, de 47\% en 2001 a 84\% para 2012 (Cuadro 3), siendo los kichwas y los waorani los que presentaron los cambios más significativos. En contraste, con respecto al piso mejorado, el cambio es mínimo porque de forma general subió solamente de 3 a 7\%, o sea, casi todos seguían con pisos de tierra o tablones. Otro elemento relevante es que estas poblaciones incrementaron considerablemente su acceso a la luz eléctrica porque aumentó de 27 a $78 \%$, con incrementos grandes en todas las etnias debido a las nuevas conexiones a lo largo de las carreteras de acceso o a los generadores comunitarios y los paneles solares.

Un indicador básico de condición de vivienda, y que es sumamente importante para la salud, es el tipo de servicio higiénico. Por lo general, en la Amazonía el mejor servicio que se puede esperar es una letrina propia. Para estas poblaciones, el acceso a una letrina no subió a nivel global, pues se mantiene en $16 \%$ para los dos años (Cuadro 3).

Se preguntó sobre un gran número de pertenencias del hogar (si tenían mesa, cama, cocineta, refrigerador, radio, televisión, escopeta, bicicleta, canoa, generador de luz, etc.). Se vislumbraron grandes aumentos, y para entender el fenómeno, se presenta el ejemplo de la televisión. El aumento de este bien es alto a nivel general, así como por etnia, y tiene relación con el acceso a la electricidad. Dicho aparato abre a los miembros del hogar a muchas influencias culturales externas, tanto negativas como positivas. Por ejemplo, en 2001 pocos hogares tenían una televisión, pero en las visitas a las comunidades tres años después, para la entrega de resultados, a pesar de que todavía no tenían acceso a luz pública, ya estaban comprando televisiones y eran utilizados con la energía de los generadores propios que funcionaban con gasolina. Esto dio lugar a que se crearan nuevos espacios sociales y de reunión, donde después de la cena varias familias se reunían en un hogar vecino que tenía televisión para mirar películas o telenovelas. Es muy probable que los escenarios mostrados por este medio presentaran a las poblaciones nuevos patrones de vida, roles sociales diferentes, formas de consumo y hasta nuevas necesidades, así como también información respecto a nuevos tipos de hogar y hasta de salud sexual y reproductiva.

\section{Actividades económicas}

Las poblaciones indígenas están involucradas en una gran variedad de actividades económicas para sostenerse, tanto tradicionales que dependen de los recursos naturales del bosque como, cada vez más, actividades relacionadas con el mercado. Una de las actividades tradicionales es la cosecha de plantas 


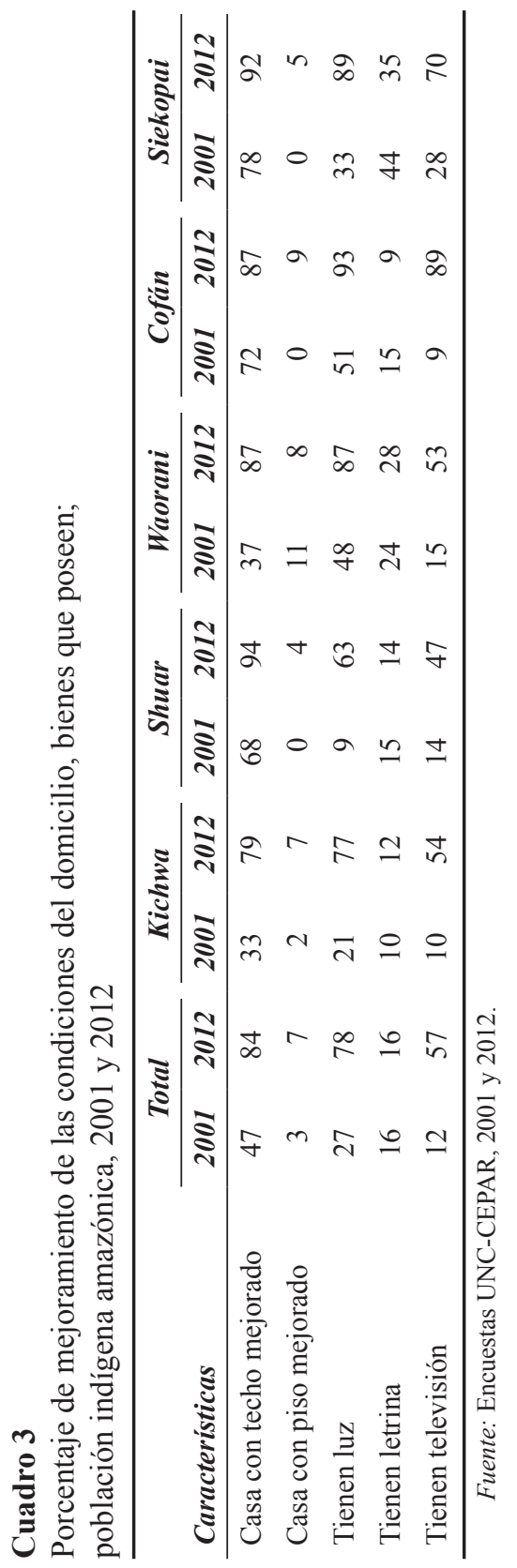


medicinales. En el Cuadro 4 se aprecia que en esta actividad casi no se encuentran mayores diferencias a nivel global. La recolección de medicina tradicional es importante (más del $70 \%$ lo hace) porque es una actividad cargada de valor social y cultural, y representa una acumulación de prácticas ancestrales de selección, manejo y conservación de conocimientos que se han transmitido de una generación a otra.

Por otro lado, las actividades tradicionales de subsistencia como la pesca y la caza tienden a bajar. A nivel general, la caza bajó de 72 a 48\%. Los que menos presentaron una baja son los cofanes (de 80 a 71\%), sin duda debido a su necesidad de responder a la falta de ingresos del turismo. Según las respuestas a las otras preguntas de la encuesta, la caza tiende a bajar porque es más difícil encontrar a los animales, requiere más tiempo, esfuerzo y recorrer mayores distancias para poder cazar al animal. De la misma manera, la pesca disminuyó, aunque no de forma tan significativa como la caza: a nivel general, de $85 \%$ en 2001, descendió a 68\% en 2012 .

Una actividad tradicional y fundamental de subsistencia, que se está convirtiendo cada vez más en una parcialmente orientada al mercado, es la agricultura. Las comunidades investigadas presentan una disminución modesta respecto al número de hectáreas dedicadas al cultivo: de 2.9 a 2.4 ha (Cuadro 5). Sólo los waorani y los siekopais presentaron aumentos de uso de tierra en la agricultura, mientras hubo bajas grandes para los shuar, seguidos por los kichwas. En los datos sobre el porcentaje de hogares que "limpiaron" terrenos para cultivar en los últimos tres años, a nivel global se redujo poco, de 88 a $82 \%$. Sobre las diferencias por etnia, subió solamente entre los siekopais, facilitado por el nuevo acceso vial durante la década, mientras bajó más entre los waorani y los kichwas, pero aún eran las dos etnias con mayor participación en la tala de bosques en 2012. El último dato sobre el área agrícola, y más útil que el porcentaje antes mencionado, es el área talada en los últimos tres años, que a nivel global descendió mucho más que la participación en la actividad, pues cayó por más de $25 \%$ hasta llegar a 1.5 ha. Para unas etnias disminuyó aún más, como los shuar y kichwas, mientras tanto aumentó entre los waorani. Aunque no se dispone de datos confiables en las encuestas sobre la tala de árboles para vender porque por lo general es ilegal; sin embargo, vimos bastantes pilas de tablones y tabletas al lado de las carreteras esperando camiones para su traslado.

En contraste con la agricultura, hubo un incremento de la actividad ganadera, de 15 a $27 \%$. Es interesante anotar las diversas tendencias que se presentan por etnia, tal como se puede apreciar en el Cuadro 5. Los datos más significativos son para los shuar, con quienes subió a más del doble la actividad al pasar de 24 a 63\%, mientras los siekopais la disminuyeron de 68 a 19\%. Al 


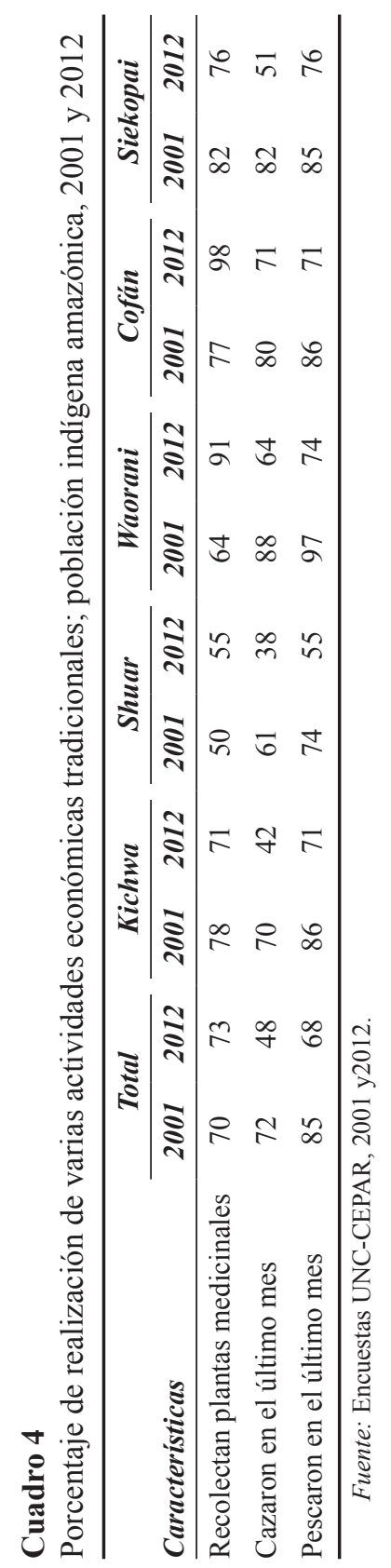




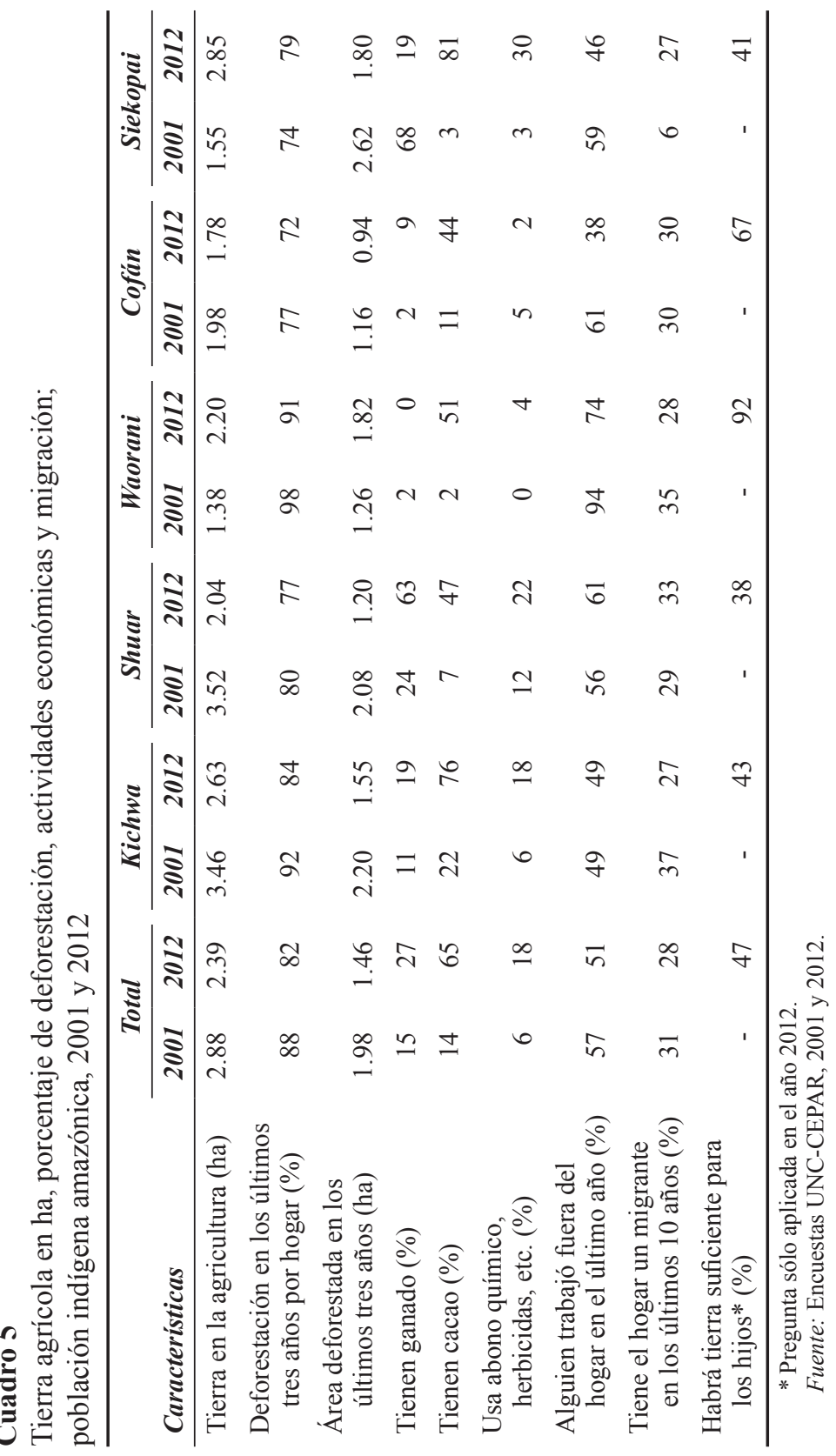


mismo tiempo, los waorani y los cofanes se encuentran a niveles muy bajos, pues son ellos quienes se mantienen más orientados a la vida tradicional y menos hacia el mercado. La caída drástica de los siekopais tiene una explicación única, y además es un buen indicador de las fallas en los programas de asistencia a las poblaciones indígenas cuando el programa es ajeno a su cultura y experiencia (véase la Introducción). A pesar de esto, y al gran aumento entre los shuar, que siempre han estado más orientados al mercado e incluso a la ganadería, es la tendencia entre los kichwas la más importante, pues son la población indígena más numerosa en la zona; ello sugiere que están modificando sus usos de la tierra, lo que implica más deforestación en el futuro.

Para el primer año de estudio, 2001, el cacao no era un producto comercial sustancial, pero se volvió central para los años siguientes y así se mantiene hasta la actualidad. Globalmente se puede apreciar su aumento de forma considerable, de 14 a $65 \%$; la tendencia indica que sus actividades agrícolas se están enfocando en el mercado porque no aumenta el uso de la tierra para la agricultura ni la deforestación, pero sí se incrementa el cultivo de cacao. Por lo tanto, se encuentran cambiando el uso de la tierra para estos productos comerciales y en el futuro pueden seguir ampliando la frontera agrícola, dado que las comunidades necesitan más recursos para la compra de más bienes y servicios (luz, salud, educación formal, alimentos procesados), por lo que mediante el cacao pueden acceder a recursos monetarios de forma continua durante todo el año. Por etnia, la que presenta los cambios más grandes son los siekopais (de 3 a $81 \%$ ), seguidos por los kichwas (22 a 76\%).

Otro indicador sobre la agricultura, que tiene elementos de tecnología "moderna" en relación con el mercado externo, y que complementaría la situación encontrada respecto a los dos indicadores anteriores -aumentos de ganado y cacao-, es el uso de abonos químicos, herbicidas y pesticidas. Para 2001, sólo el 6\% usaba alguno de éstos, mientras que para 2012 subió a 18\%, lo cual indica una importante penetración del mercado con su tecnología agrícola. Todas las etnias aumentaron su uso, a excepción de los cofanes y un poco los waorani.

Un indicador clave del proceso de incorporación al mundo externo es el porcentaje de hogares con algún miembro que trabaje por dinero afuera del hogar (sea dentro o fuera de la comunidad). El indicador disponible presenta una disminución mínima, de 57 a 51\%, a nivel global. Por etnias, subió un poco entre los shuar y se redujo bastante entre las tres más pequeñas, los waorani, los cofanes y los siekopais, y entre la población indígena principal de la zona, los kichwa, no hubo cambio alguno. Esta información de estabilidad sugiere que, por ahora, se están más bien manteniendo sus actividades tradicionales de subsistencia. 
Otro asunto relacionado con la economía del hogar es la migración de las personas que van a vivir fuera de sus comunidades. Después de la encuesta de 2001, en la que se encontró gran interés en la educación de sus hijos, se estaba anticipando una mayor emigración en busca de más trabajo y nuevos estilos de vida (facilitada por el importante mejoramiento en la calidad de las vías durante esa década). Sin embargo, la emigración no ocurrió, excepto en la pequeña población de los siekopais, porque de $6 \%$ en 2001, subió a 27\% en 2012, probablemente ligada a la red vial pavimentada que llegaba a sus dos comunidades. Sin embargo, para el resto de las etnias no se observa un cambio en el porcentaje de hogares que cuentan con migrantes.

En el cuestionario de 2012 incluimos una pregunta sobre si piensa que habrá tierra suficiente para los hijos en el futuro o no, lo que generó un dato interesante para saber las expectativas que tienen respecto a sus tierras. Todas las etnias, a excepción de los waorani, presentan expectativas bajas sobre la disponibilidad de tierras suficientes para las generaciones futuras, lo que puede deberse al crecimiento demográfico y a los cambios a los que se han estado enfrentando respecto a sus actividades tradicionales de subsistencia.

\section{Discusión}

Respecto a la fecundidad de la población indígena amazónica, este documento evidencia que no se presentan cambios demográficos significativos, apenas bajas ligeras en la fecundidad, y por eso hay un alto crecimiento demográfico. Los datos sugieren un cambio en la valoración de las familias grandes con respecto al número de hijos nacidos, aunque hasta 2012 esto no se había presentado efectivamente (Davis, Gray y Bilsborrow, 2015), pero es probable que van a comenzar la tradicional transición demográfica hacia una fecundidad menor, proceso casi global que se encuentra en marcha en Ecuador, como en casi toda América Latina, a partir de los años setenta (Centro de Estudios de Población y Desarrollo Social, 2005; Carr, Pan y Bilsborrow, 2006). De hecho, la reducción en el deseo de tener hijos - expresada en las opiniones de los hogares- pudiera tener relación con la opinión de la mayoría, que respondió que cree que no van a tener suficiente tierra para sus hijos en el futuro. ${ }^{8}$

${ }^{8}$ Esto se corrobora con una investigación cualitativa realizada en el año 2013 por la primera autora sobre la fecundidad en una submuestra a estas mismas comunidades indígenas. 
Otro factor clave en el desarrollo socioeconómico de las poblaciones indígenas es la educación o el capital humano. Esto ha presentado cambios importantes: para 2012 casi el 100\% de los niños de edad escolar asistían a la escuela primaria, y cuatro de cinco a la secundaria, siendo los dos valores mucho mayores que los de 2001, lo cual constituye un real cambio educativo en marcha. La educación está direccionada, en cierta medida, como una nueva forma de herencia dejada por los padres, poco a poco suplantando la próxima escasez de otros elementos, como son la tierra y un hábitat adecuado -el cual cada vez es menos prístino y hasta degradado por el petróleo, la deforestación y la caza excesiva-. De algún modo, esta educación puede estar dirigida al mejor cumplimiento de los objetivos del mercado para ayudar a los hijos a integrarse de mejor forma en éste. Pero es interesante que aun con mucha más educación, hasta ahora no hay más emigración, y en cierta manera mantienen sus costumbres y actividades económicas tradicionales en cuanto a la agricultura de subsistencia, complementada con el cultivo del cacao y el trabajo remunerado, presentándose sólo bajas significativas en la caza y la pesca.

Los datos de las dos encuestas disponibles indican un sinnúmero de mejoramientos en las condiciones físicas de las poblaciones indígenas amazónicas durante los once años, con menor mortalidad y mejor salud, mejoramiento en sus casas y más bienes, transformándose hacia sociedades más "modernas". Pero hay ciertos elementos que no están cambiando de esa manera. Como se anotó, un ejemplo es la emigración de los miembros de las comunidades, pues según las encuestas, en vez de haber subido, que es lo que se esperaría después de grandes mejoramientos en las vías de acceso y en la educación de sus hijos, ésta aún no se presenta. Por lo tanto, en cierta medida se puede deducir que las comunidades todavía cuentan con sus fuentes básicas y tradicionales de subsistencia para sostener sus vidas tradicionales, sobre todo por medio de la agrosilvicultura. Es decir, se puede anotar que tienen bastante tierra para seguir viviendo en sus comunidades, aunque queda por conocer su estado nutricional, que no se investigó en las encuestas. Ante esto, puede presentarse cierto empeoramiento en lo que corresponde a la alimentación, pues pese a las bajas en las actividades de caza y pesca, fuentes principales de sus proteínas, tienen la posibilidad de realizar más compras en los pueblos, por las nuevas transformaciones respecto a su mayor vinculación con el mercado mediante la venta de productos como el cacao, así como por su vinculación con el trabajo laboral remunerado.

En función de los resultados analizados, y estableciendo categorías a nivel de cada etnia para identificar cuál es la que más cambios presenta, la 
primera población con mayores modificaciones en sus patrones sociales y económicos son los siekopai, pues son quienes han tenido contacto más directo con las empresas petroleras y palmicultoras y, sobre todo, mayor y nuevo acceso vial, lo que les ha generado un mayor acceso a las zonas urbanas y a los mercados.

A esta etnia le siguen los waorani -antes los más aislados en el bosque y los mejores cazadores-, quienes están comenzando a presentar cambios profundos en sus patrones sociales y económicos. Esto nuevamente tiene relación con la presencia de las empresas petroleras en sus territorios: aunque sea temporal, todavía sigue provocando efectos de forma marcada, dado que su contacto externo se ha dado apenas en los últimos 60 años. Resalta que en esta última década las mujeres waorani se han organizado para emprender una lucha permanente por sus derechos y los de la naturaleza.

Le sigue la etnia dominante de la Amazonía, la kichwa, la cual presenta cambios no a los niveles de la siekopai y la waorani, porque se trata de una población que ha tenido mayor contacto continuo con los otros actores analizados; por lo tanto, sus cambios se reflejan en que están modificando sus condiciones de vida por el mayor acceso al trabajo remunerado, así como a bienes.

Los shuar siguen presentando cambios fuertes en el aumento en su ganadería, aunque ya en 2001 estaban más orientados hacia el mercado que las otras etnias, y esto puede deberse a que son una población colona de esta región. Sin embargo, han seguido manteniendo otras actividades de subsistencia como la caza, la pesca y la recolección de productos forestales.

Por último, la etnia que presentó menos cambios en casi todas las tendencias analizadas en este documento fue la de los cofanes. Ello puede estar relacionado con que son comunidades cuyos contactos con otros actores se encuentran limitados por la distancia, el casi nulo acceso a sus comunidades, su ubicación dentro de las reservas y la poca presencia de otros actores cerca de sus territorios.

\section{Conclusiones}

A partir del enfoque tomado para el desarrollo de este documento, partimos de que las poblaciones cambian y establecen relaciones con el ambiente no de forma única y simple, sino que se hace necesario hacer el reconocimiento de otros factores, internos y externos, que inducen estos cambios.

Hemos encontrado con este estudio que la situación para las poblaciones indígenas sí se ha alterado en el tiempo analizado, y que las modificaciones 
tienen impactos sobre los hogares y sus relaciones con el ambiente. Las actividades de autosubsistencia presentan cambios importantes. Sobre todo, se presenta una reducción de la caza y la pesca, lo cual en cierta medida puede explicarse en función de la teoría de la respuesta multifásica, pues la disminución de las actividades de autosubsistencia fue direccionada hacia un cambio de uso de suelo a favor de los productos agropecuarios destinados para la venta. Entonces, el acceso a los recursos monetarios, así como sus nuevas vinculaciones laborales, les pudo haber permitido comprar los alimentos, con lo que disminuyeron así estas actividades.

De la misma forma, tal como lo plantea la livelihood theory, esta modificación en las actividades de autosubsistencia también implica el cambio en la distribución de los miembros en los distintos tipos de actividades. Por tanto, la mayor vinculación con el mercado reduce estas actividades de autosubsistencia, a lo que se suma el mayor acceso a la educación por parte de esta población y, dado que es joven, va también a limitar el tiempo y el número de personas que se dediquen a dichas actividades para poder cumplir con el tiempo que demanda la educación formal. Sobre todo en un futuro cercano, estas poblaciones con mayor educación y con posibles vinculaciones laborales limitarán aún más dichas actividades.

A pesar de que tienen más contacto con otros actores y acceso a la educación, se esperaba un mayor cambio de sus actividades de autosubsistencia, pero los datos indican que si bien hay cambios en el tiempo, éstos no son tan profundos ya que todavía son actividades importantes. Sin embargo, existe el reconocimiento de la situación de su territorio y la limitación (en espacio y condiciones) para las poblaciones futuras.

Las actividades de agrosilvicultura con base en las formas tradicionales de uso de suelo (roza, quema y descanso largo de la tierra luego de tres a cinco años de su uso) va a tener efectos porque el uso de la tierra de la Amazonía bajo este modelo le da sustentabilidad. Pero hay nuevas formas de uso y manejo del lugar, que en este caso se evidencian con el mayor uso de la tierra para la inmersión y la siembra del cacao, la palma africana y los pastizales para el ganado, actividades que se encuentran ligadas completamente al mercado y que implican también mayor uso de químicos y fertilizantes, dada la baja calidad de los suelos amazónicos y la cantidad de pestes. Por tanto, se están presentando modificaciones y aun de forma más intensa por la presencia de los otros actores, como los colonos, las empresas extractivas y el Estado (Vasco, Bilsborrow y Torres, 2015).

Para finalizar, este artículo pretende mostrar que debemos entender que los pueblos indígenas se adaptarán a cambiar, apoyándose en sus organizaciones sociales internas, como ya lo han hecho, como baluarte en contra de 
la homogeneización de sus culturas y para proteger los intereses socioeconómicos de sus comunidades. Uno de los elementos más importantes para su éxito, aparte de su fuerza política, es la ventaja de contar con grandes extensiones de tierra y utilizar este activo para participar en el crecimiento, pero bajo sus sistemas socioculturales y económicos porque el desarrollo económico en la zona (por la agricultura, la ganadería, las plantaciones forestales y el crecimiento urbano) crea un entorno favorable para sus negocios y el aumento de las oportunidades de empleo y trabajo. Pero hay que tener en cuenta que estas características no deben ser impuestas, sino que tienen que responder a sus dinámicas sociales y culturales, para que logren un mejoramiento en sus condiciones de vida en función de sus derechos de autodeterminación.

\section{Bibliografía}

Argüello, O. (1981). Estrategias de supervivencia: un concepto en busca de su contenido. Estudios Demográficos y Urbanos, 15(2), 190-203. Recuperado de https://estudiosdemograficosyurbanos.colmex.mx/index. php/edu/article/view/511/504

Asner, G., Knapp, D., Broadbent, E., Oliveira, P., Keller, M. y Silva, J. (2005). Selective logging in the Brazilian Amazon. Science, 310, 480-482. Recuperado de https://www.fs.fed.us/global/iitf/pubs/ja_iitf_2005_asner 001.pdf

Barbieri, A., Bilsborrow, R., Mena, C., Pan, W. y Torres, B. (2003). Changes in land cover and land use over time in the Ecuadorian Amazon. Ponencia presentada en el 99th Meeting of Association of American Geographers, Nueva Orleans, LA, Estados Unidos.

Bass, M., Finer, M., Jenkins, C., Kreft, H., Cisneros-Heredia, D., McCracken, S., ... Kunz, T. (2010). Global conservation significance of Ecuador's Yasuní National Park. PLoS ONE, 5(1), 1-22. Recuperado de https:// www.ncbi.nlm.nih.gov/pmc/articles/PMC2808245/

Bilsborrow, R. (1987). Population pressures and agricultural development in developing countries: A conceptual framework and recent evidence. World Development, 15(2), 183-203. Recuperado de https://www.science direct.com/science/article/abs/pii/0305750X87900775

Bilsborrow, R., Barbieri, A. y Pan, W. (2004). Changes in population and land use over time in the Ecuadorian Amazon. Acta Amazónica, 34(4), 635-647. Recuperado de http://www.scielo.br/scielo.php?script=sci_art text\&pid=S0044-59672004000400015 
Bozigar, M., Gray, C. y Bilsborrow, R. (2016). Oil extraction and indigenous livelihoods in the Northern Ecuadorian Amazon. World Development, 78, 125-135. Recuperado de https://www.sciencedirect.com/science/ article/pii/S0305750X15002570

Byron, N. y Arnold, M. (1999). What futures for the people of the tropical forests? World Development, 27(5), 789-805. Recuperado de https://www. sciencedirect.com/science/article/pii/S0305750X9900025X

Carr, D., Pan, W. y Bilsborrow, R. (2006). Declining fertility on the frontier: The Ecuadorian Amazon. Population and Environment, 28(1), 17-39. Recuperado de https://www.ncbi.nlm.nih.gov/pmc/articles/PMC 2720552/

Centro Estudios Población y Desarrollo Social (CEPAR). (2005). Encuesta Demográfica y de Salud Materna e Infantil Endemain. Quito, Ecuador: CEPAR.

Chiriboga, M. (1984). Formas tradicionales de organización social y económica en el medio indígena. Quito, Ecuador: Ministerio de Bienestar Social, Oficina Nacional de Asuntos Indígenas.

Conaie. (2014). Situación de las nacionalidades del Ecuador. Quito, Ecuador: Confederación de Nacionalidades Indígenas del Ecuador. Recuperado de la página de internet del organismo (fecha de consulta: 20 de marzo de 2018).

Davis, K. (1963). The theory of change and response in modern demographic history. Population Index, 29(4), 345-366. Recuperado de https://www. ssc.wisc.edu/ $\sim$ walker/wp/wp-content/uploads/2012/04/Davis1963.pdf

Davis, J., Gray, C. y Bilsborrow, R. (2015). Delayed fertility transition among indigenous women: A case study in the Ecuadorian Amazon. International Perspectives on Sexual and Reproductive Health, 41(1), 1-10. Recuperado de https://www.ncbi.nlm.nih.gov/pmc/articles/PMC439 4206/

Ellis, F. (2000). Rural livelihoods and diversity in developing countries. Oxford, Reino Unido: University Press

Finer, M., Jenkins, C., Pimm, S., Keane, B. y Ross, C. (2008). Oil and gas projects in the western Amazon: Threats to wilderness, biodiversity, and indigenous peoples. PLoS ONE, 3(8), e2932. Recuperado de https:// journals.plos.org/plosone/article/file?id=10.1371/journal.pone. 0002932\&type $=$ printable

Fontaine, G. (2006). La globalización de la Amazonía: una perspectiva andina. Íconos. Revista de Ciencias Sociales, 25, 25-36. Recuperado de https://www.researchgate.net/publication/26484065_La_globalizacion_ de_la_Amazonia_una_perspectiva_andina_Dossier 
Forman, R. y Alexander, L. (1998). Roads and their major ecological effects. Annual Review of Ecology and Systematics, 29, 207-231. Recuperado de https://www.annualreviews.org/doi/10.1146/annurev.ecolsys.29.1.207

Goodman, R. y Kish, L. (1950). Controlled selection: A technique in probability sampling. Journal of the American Statistical Association, 45(251), 350-372. Recuperado de https://amstat.tandfonline.com/doi/abs/10.108 0/01621459.1950.10501130\#.XDjXwlxKiUk

Gray, C., Bilsborrow, R., Bremner, J. y Lu, F. (2008). Indigenous land use in the Ecuadorian Amazon: A cross-cultural and multilevel analysis. Human Ecology, 36(1), 97-109. Recuperado de https://link.springer. com/article/10.1007/s10745-007-9141-6

Hecht, S. (2012). From eco-catastrophe to zero deforestation? Interdisciplinarities, politics, environmentalisms and reduced clearing in Amazonia. Environmental Conservation, 39(1), 4-19. Recuperado de https://doi. org/10.1017/S0376892911000452

Keller, M., Bustamante, M., Gash, J. y Dias, P. (eds.) (2009). Amazonia and global change. Washington, DC: American Geophysical Union.

Kish, L. (1965). Survey sampling. Nueva York, NY: John Wiley and Sons.

Lu, F. y Bilsborrow, R. (2011). A cross-cultural analysis of human impacts on the rainforest environment in Ecuador. En R. P. Cincotta y L. J. Gorenflo (eds.), Human population: Its influences on biological diversity (pp. 127-151). Berlín-Heidelberg: Ecological Studies.

Lu, F., Bilsborrow, R. y Oña, A. (2010). Modos de vivir y sobrevivir. Un estudio transcultural de cinco etnias en la Amazonia Ecuatoriana. Quito, Ecuador: Abya-Yala.

Macas, L. (2002). La lucha del movimiento indígena en el Ecuador. Boletín ICCI-ARY RIMAY, 4(37). Recuperado de http://icci.nativeweb.org/boletin /37/macas.html

Murphy, L., Bilsborrow, R. y Pichón, F. (1997). Poverty and prosperity among migrant settlers in the Amazon rainforest frontier of Ecuador. The Journal of Development Studies, 34(2), 35-66. Recuperado de https://www.tand fonline.com/doi/pdf/10.1080/00220389708422511?needAccess=true

Perz, S., Caldas, M., Arima, E. y Walker, R. (2007). Unofficial road building in the Amazon: Socioeconomic and biophysical explanations. Development and Change, 38(3), 529-551. Recuperado de https://onlinelibrary. wiley.com/doi/full/10.1111/j.1467-7660.2007.00422.x

Pimentel, D., McNair, M., Buck, L., Pimentel, M. y Kamil, J. (1997). The value of forests to world food security. Human Ecology, 25(1), 91-120. Recuperado de https://www.jstor.org/stable/4603227?seq=1\#metadata info_tab_contents 
Rice, R., Sugal, C., Ratay, S. y Fonseca, G. (2001). Sustainable forest management: A review of conventional wisdom (Advances in Applied Biodiversity, 3). Washington, DC: Conservation International. Recuperado de http://www.mekonginfo.org/assets/midocs/0001776-environ ment-sustainable-forest-management-a-review-of-conventional-wis dom.pdf

Salinas, V. y Bilsborrow, R. (2016). Diferencias en la fecundidad por etnia indígena en la Amazonía del Ecuador. Ponencia presentada en el VII Congreso de la Asociación Latinoamericana de Población y XX Encuentro Nacional de Estudios de Población, Foz do Iguaçu / PR-Brasil, 17 y 22 de octubre.

Santos, F. (1996). Introducción. Hacia una antropología de lo contemporáneo en la Amazonía indígena. En F. Santos Granero (comp.), Globalización y cambio en la Amazonía Indígena (pp. 7-46). Quito, Ecuador: Flacso / ABYA-YALA.

Suárez, E., Morales, M., Cueva, R., Utreras, V., Zapata-Ríos, G., Toral, E. y Vargas, J. (2009). Oil industry, wild meat trade and roads: Indirect effects of oil extraction activities in a protected area in north-eastern Ecuador. Animal Conservation, 12(4), 364-373. Recuperado de https://doi. org/10.1111/j.1469-1795.2009.00262.x

Vasco, C., Bilsborrow, R. y Torres, B. (2015). Income diversification of migrant colonists vs. indigenous populations: Contrasting strategies in the Amazon. Journal of Rural Studies, 42, 1-10. Recuperado de https:// www.sciencedirect.com/science/article/pii/S074301671530019X

\section{Acerca de los autores}

Victoria Salinas Castro es doctorante en Demografía en la Universidad Federal de Minas Gerais, Cedeplar, Brasil; cuenta con una maestría en Estudios Socioambientales por la Facultad Latinoamericana de Ciencias Sociales (Flacso-Ecuador). Trabaja en el desarrollo e implementación de herramientas teóricas-metodológicas para investigar la situación y dinámica demográfica de las poblaciones indígenas y afrodescendientes para el diseño y ejecución de políticas públicas interculturales. Sus líneas de investigación se centran en temas de fecundidad, migración y ámbito socioambiental de dichas poblaciones. Es miembro de la Red Andino Amazónica de Estudios de Población y de la Asociación Latinoamericana de Estudios de Población. ORCID: https://orcid.org/0000-0002-7007-7260

Es autora de: 
Salinas Castro, V. (2010). Ambiente y cultura en la transmisión y prevención de enfermedades. Editorial Académica Española.

Richard E. Bilsborrow es profesor de Bioestadística y profesor adjunto en las facultades de Planificación Urbana y Regional, Economía, Geografía y Medio Ambiente, de la Universidad de Carolina del Norte en Chapel Hill, NC, Estados Unidos. Es economista-demógrafo, con títulos académicos en Economía (licenciatura por el Carleton College; doctorado por la Universidad de Michigan, Ann Arbor) y un posdoctorado en Demografía por la Universidad de Princeton. Trabaja en los temas de desarrollo económico, migración interna e internacional, uso de tierra y deforestación, metodologías de investigación y recolección de datos, con enfoque en América Latina. Es miembro activo de la Population Association of America y de la Unión Internacional para el Estudio Científico de Población; es asesor de la Organización Internacional para las Migraciones; y ha brindado muchos asesoramientos a Naciones Unidas, OIT, FAO y a distintos gobiernos. También ha diseñado, implementado y analizado cinco encuestas de colonos e indígenas en la Amazonía Ecuatoriana. ORCID: https://orcid.org/0000-0002-0053-7356 Entre sus publicaciones destacan:

Bilsborrow, R. (2016). Concepts, definitions and data collection approaches. En M. White (ed.), International handbook of migration and population distribution (pp. 109-156). Dordrecht, Países Bajos: Springer.

Lu, F., Bilsborrow, R. y Oña, A. (2012). Modos de vivir y sobrevivir: un estudio transcultural de cinco etnias en la Amazonía Ecuatoriana. Quito, Ecuador: Abya Yala.

Bilsborrow, R., Oberai, A. y Standing, G. (1984). Migration surveys in lowincome countries: Guidelines for survey and questionnaire design. Londres, Inglaterra: Croom-Helm.

Clark L. Gray es profesor asociado de Geografía en la Universidad de Carolina del Norte en Chapel Hill, NC, Estados Unidos. Es geógrafo de Población, con un doctorado en Geografía de la Universidad de Carolina del Norte.

Es autor de:

Bozigar, M., Gray, C. L. y Bilsborrow, R. E. (2016). Oil extraction and indigenous livelihoods in the northern Ecuadorian Amazon. World Development, 78, 125-135.

Davis, J., Gray, C. L. y Bilsborrow, R. (2015). Delayed fertility transition among indigenous women: A case study in the Ecuadorian Amazon. International Perspectives on Sexual and Reproductive Health, 41(1), 1-10. 
Gray, C. L., Bozigar, M. y Bilsborrow, R. E. (2015). Declining use of wild resources by indigenous peoples of the Ecuadorian Amazon. Biological Conservation, 182, 270-277.

Recepción: 10 de julio de 2017.

Aceptación: 2 de mayo de 2018. 